\title{
SUPERSONIC LASER DEPOSITION OF TUNGSTEN
}

\author{
Marshall Jones \\ GE Global Research \\ Niskayuna, New York, USA
}

\author{
Andrew Cockburn \\ University of Cambridge \\ Cambridge, UK
}

\author{
Martin Sparkes \\ University of Cambridge \\ Cambridge, UK
}

\author{
William O'Neill \\ University of Cambridge \\ Cambridge, UK
}

\author{
Rocco Lupoi \\ Trinity College Dublin \\ Dublin, Ireland
}

\begin{abstract}
Near fully dense tungsten coatings onto molybdenum substrates have been demonstrated using the Supersonic Laser Deposition (SLD) process. This is a characteristic that is not readily achievable with refractory materials. The tensile strength of the tungsten deposited coatings is similar to that of wrought tungsten, with no evidence of melting or substrate grain growth. The tungsten coating to a molybdenum substrate shows no evidence of melting or substrate grain growth. The SLD process is a novel deposition method that is based upon Cold Spay (CS) principles. In this technique the deposition velocities can be significantly lower than those required for effective bonding in $\mathrm{CS}$ processing. The addition of laser heating alters the mechanical properties of the materials at the deposition site. The results have shown that SLD is able to deposit tungsten with unique interface bonding and desirable properties as opposed to other deposition processes for refractory materials.
\end{abstract}

Keywords: Cold Spray, Supersonic Laser Deposition, Tungsten, Coatings, Bend Test.

\section{INTRODUCTION}

Tungsten is a refractory metal which is fairly ductile in its purest state but it becomes brittle when contaminant levels are similar to those found in commercially available power. The melting temperature of $3410{ }^{\circ} \mathrm{C}$ is the highest of all metals. The density of tungsten is normally $19.3 \mathrm{~g} / \mathrm{cm}^{3}$ at $20{ }^{0} \mathrm{C}$. The room temperature tensile has a range of $600-$
$3450 \mathrm{MPa}$ [1]. Its applications include filaments for light bulbs, emitters and targets for X-ray tubes. When used as target material for generating X-rays, an electron beam impinges on the target. After some period of time, the tungsten target is compromised due to the electron beam interaction with the material. This may include even "mud cracking" defects on the electron beam race track. Targets are typically discarded after so many hours of use and with the occurrence of undesirable defects. The targets are discarded because there has not been a means to refurbish them such that they could be continued to be used.

The development of a practical method for the deposition of tungsten would allow X-ray targets to be repaired rather than discarded. Currently the options available for the deposition of tungsten are limited. One established method is through chemical vapor deposition (CVD) using $\mathrm{WF}_{6}$ as precursor. Although this technique has been used for the manufacture of X-ray targets [2], the low deposition rate of 100-300 $\mu \mathrm{m}$ per hour limits its practical use in this application.

Deposition of tungsten via the consolidation of micron scale powder has been reported using selective laser melting (SLM) and Cold Spray (CS) [3,4]. Although deposition has been achieved with SLM, work reported details deposits which are either alloyed to allow full density to be achieved [5], or porous with densities not exceeding $82 \%$ [3]. 
The deposition of W-Ni-Fe powders using cold spray has been reported [4]. When tungsten powder was used, coatings of less than $10 \mu \mathrm{m}$ thickness were produced despite using powder feed rates comparable to those used in the deposition of $\sim 50 \mu \mathrm{m} \mathrm{W-Ni-Fe} \mathrm{coatings,} \mathrm{suggesting} \mathrm{that} \mathrm{build}$ rate is very low.

SLD [6] is a process under development at the University of Cambridge. In this technique, which is similar in working mechanisms to conventional CS, the effect of using nitrogen as a carrier gas (reduced particle velocity) is compensated by the implementation by an infrared $(1.07 \mu \mathrm{m}$ wavelength) laser source to illuminate the coating zone so as to facilitate deposition.

In this paper, the application of SLD to the deposition of tungsten coatings is discussed while the suitability of the deposits for use as X-ray targets is accessed via density measurements and mechanical characterization

\section{DEPOSITION PROCESS}

The SLD system schematics are shown in Figure 1. Metal powder delivered from a high pressure feeder (Praxair 1264HP) is accelerated up to supersonic velocity through a nitrogen carrier gas within a converging-diverging nozzle. The maximum allowable nozzle inlet pressure is $30 \mathrm{bar}$ in the current system which provides a particle impact velocity in the $400-550 \mathrm{~m} / \mathrm{s}$ range depending on the size and type of material.

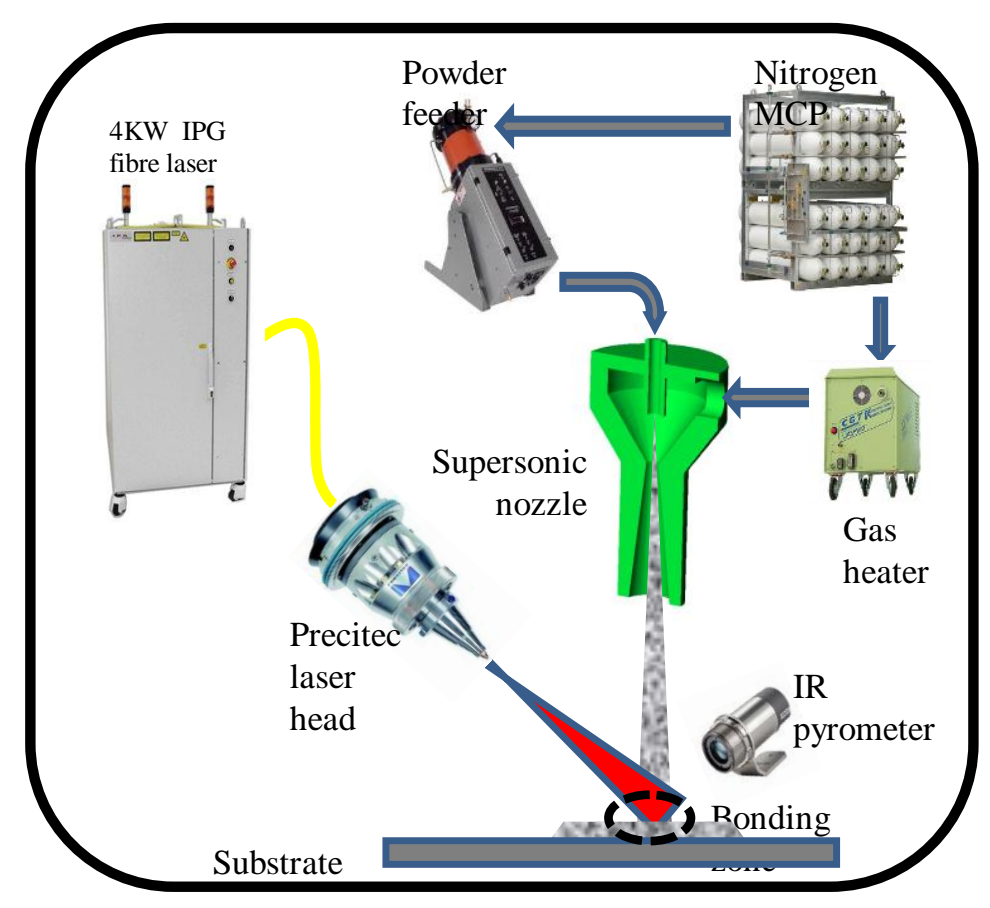

Figure 1: SLD process schematics.
As Figure 1 shows, the deposition zone is illuminated by a laser beam (IPG fiber laser with maximum power of $4 \mathrm{~kW}$ ). This is to soften the substrate material (not for melting) to enable the coating formation without the necessity of accelerating powders up to CS velocities. It has been shown that it is possible to achieve the deposition of high strength materials (such as Stellite-6 and Titanium) in a cost-efficient manner, therefore with nitrogen as the carrier gas $[7,8]$. The nitrogen gas supply is from MCP's (Manifold Cylinders Pallet). After processing, it is removed from the working chamber through an extraction system.

SLD has the potential to overcome the disadvantages of other deposition processes for tungsten, especially CS and SLM, since the process allows the impact site to be heated to above the ductile brittle transition temperature of tungsten while avoiding the need to melt the material to produce bonding.

The coatings used in this study consisted of $19 \mu \mathrm{m}$ average $\left(D_{50}\right)$ diameter tungsten powder deposited onto molybdenum substrates. Coatings for mechanical assessment were deposited using a gas pressure of $30 \mathrm{bar}$, laser power of 4 $\mathrm{kW}$, a substrate traverse rate of $10 \mathrm{~mm} / \mathrm{s}$, and a carrier gas inlet temperature of $500{ }^{\circ} \mathrm{C}$. The nozzle used in this case had a restriction cross sectional diameter of $2.7 \mathrm{~mm}$, with a total length of $200 \mathrm{~mm}$. Deposition temperature could not be recorded for the deposition of tungsten as it took place at a temperature outside the range of the SLD system's IR pyrometer. Coatings were produced by overlapping adjacent tracks of $\mathrm{W}$ and depositing multiple layers until the required coating thickness was achieved. Two layers were sufficient so as to achieve the deposition of an overall coating thickness of approximately $0.4 \mathrm{~mm}$.

\section{COATING STRUCTURE}

Metallographic examination of the SLD tungsten deposit, Figure 2(a), showed that there is no melting of the tungsten powder feedstock. The coating was chemically etched so as to reveal its structure. Typical tungsten particle sizes in the feed stock can be observed in the consolidated coating with two grains highlighted at $\sim 5.6 \mu \mathrm{m}$ and $14.7 \mu \mathrm{m}$. The coating appears to be essentially porosity free with no melting of the tungsten feedstock evident. In addition, no melting, grain growth, or any other micro-structural changes to include the formation of Heat Affected Zones (HAZ) are observed in the molybdenum substrate, as shown in Figure 2(b). 


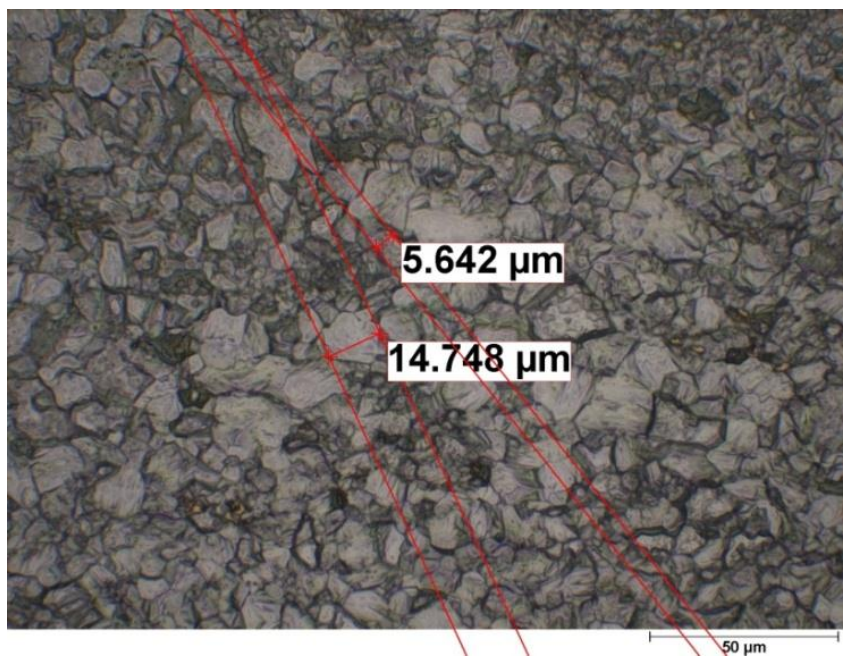

Figure 2(a): Tungsten Deposit Show No Melting of Tungsten Feedstock

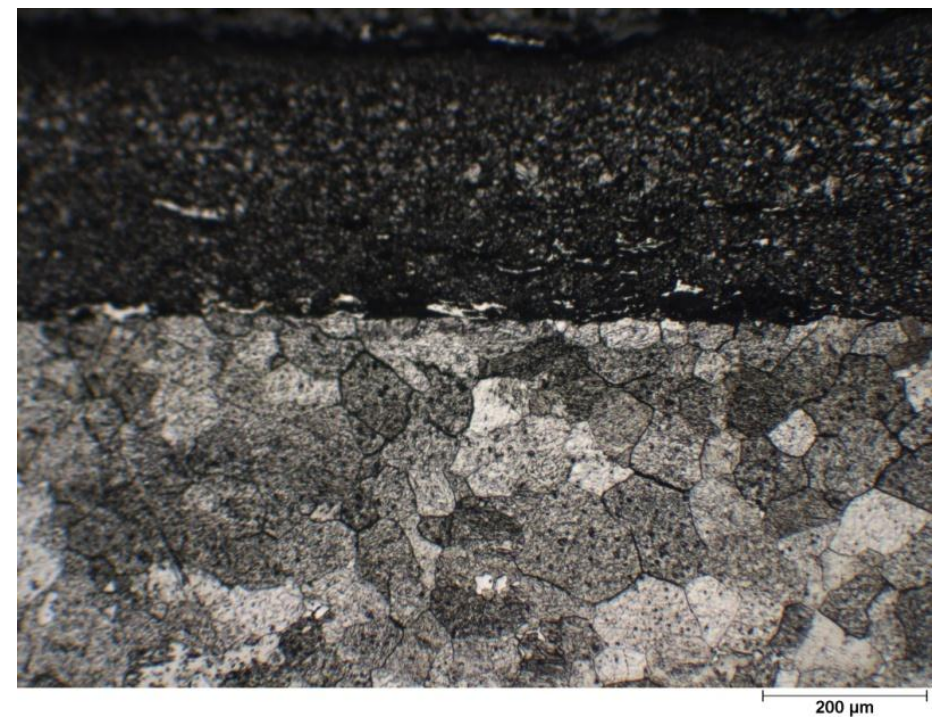

Figure 2(b): Substrate (Molybdenum) Micro-structure

To address the room temperature tensile strength of a SLD tungsten deposit, a 3-point bend test was conducted. A 3point bending test coupon was wire EDM cut out of the tungsten deposit. The nominal dimensions the test coupon were $30 \mathrm{~mm}$ length, $1 \mathrm{~mm}$ thickness and $2 \mathrm{~mm}$ width. Figure 2 shows a schematic of the 3 -bend test configuration. It shows that the support span, $L$, is $20 \mathrm{~mm}$.

The density of the SLD tungsten deposit, measured using Archimedes was $18.3 \mathrm{~g} / \mathrm{cm}^{3}$ which falls within the specification range of $18.3-18.7 \mathrm{~g} / \mathrm{cm}^{3}$ for what would be required if the technique was to be used for a X-ray target refurbishment operation [9]. This density result is $\sim 95 \%$ of the density of wrought tungsten $\left(19.3 \mathrm{~g} / \mathrm{cm}^{3}\right)$. There is probably some headroom for improving the on SLD process parameters.

\section{MECHANICAL BEHAVIOR}

To address the room temperature tensile strength of the SLD tungsten deposit, a 3-point bend test was conducted. A 3-point bending test coupon was wire EDM cut out of the deposit. The nominal dimensions of the test coupon were 30 $\mathrm{mm}$ length, $1 \mathrm{~mm}$ thickness and $2 \mathrm{~mm}$ width. Figure 2 shows a schematic of the 3-point bend test configuration. It shows that the support span, $L$, is $20 \mathrm{~mm}$.

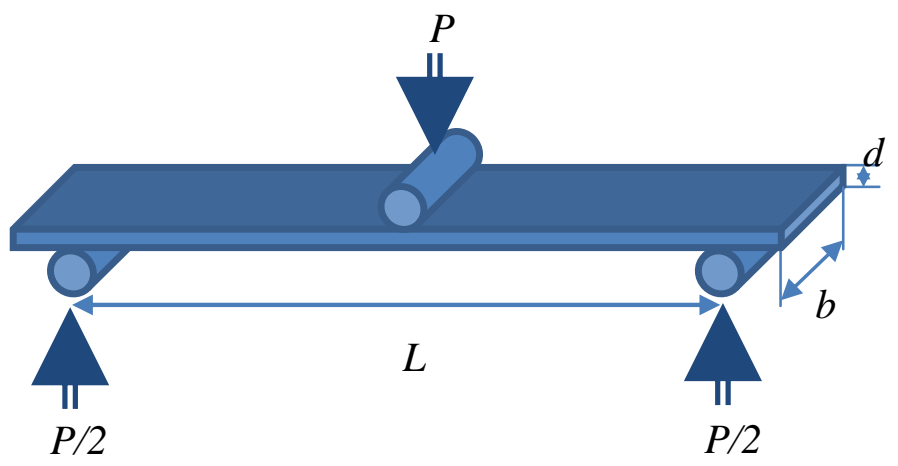

Figure 2: 3- Point Bend Test Schematic

Figure 3 shows the graph of the maximum load applied to the 3-point bend specimen before it failed. The failure load is shown to be $53.5 \mathrm{~N}$.

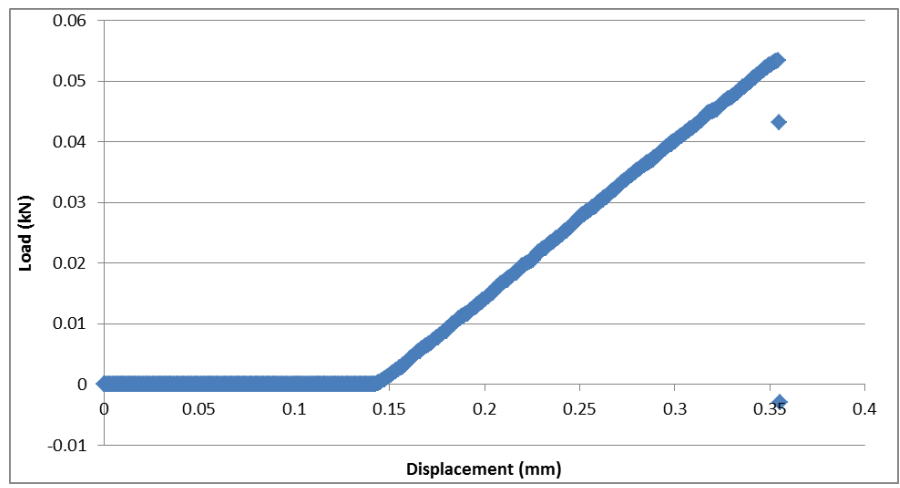

Figure 3: Failure load for 3-point bending test.

The tensile strength of the of the SLD tungsten deposit can be calculated with the following bending stress Equation 1. In the formula, $P$ is the failure load in the load in the loaddefection curve $(53.5 \mathrm{~N}), L$ is the support span $(20 \mathrm{~mm}), b$ is 
the width of the test beam $(2.02 \mathrm{~mm})$ and $d$ is the thickness of the test beam of the test beam $(1.05 \mathrm{~mm})$. The calculated stress at the outer surface at midpoint $\left(\sigma_{f}\right)$ equals to $724 \mathrm{MPa}$.

$\sigma_{f}=\frac{3 P L}{2 b d^{2}}$

Although the tungsten was a SLD deposit, the tensile strength was within the range of the tensile strength for wrought tungsten. The deposition characteristics, microstructure and mechanical behavior of SLD tungsten suggest that it may provide a viable route for the refurbishment of tungsten X-ray targets.

\section{CONCLUSIONS}

The Supersonic Laser Deposition (SLD) process was introduced. This coating technique is similar in working principles to Cold Spray (CS), however deposition is demonstrated to be possible without the necessity of accelerating metal powder up to their full critical velocity. SLD was applied to the coating of a molybdenum substrate with a tungsten deposit. This resulted in a tungsten deposit that exhibited strength and density properties that were very similar to that of wrought tungsten properties. Most importantly, there were no thermal effect resulting in no deposit-substrate melting at the interface, no tungsten feedstock melting and no molybdenum substrate grain growth.

\section{ACKNOWLEDGEMENTS}

The authors wish to express their gratitude to IPG Photonics and GE Healthcare for their valuable technical, materials, and financial support.

\section{REFERENCES}

[1] Midwest Tungsten Service, 7101 S. Adams St. \#6, Willowbrook, IL 60527

[2] Huot, G., Fellmann, V., Poirel, H., "Chemical Vapot Deposition of Tungsten Coating on X-ray Rotating Light Anodes Made of Carbon-Based Materials", proceedings of the $18^{\text {th }}$ Plansee Seminar, 2013.

[3] Zhang, D., Cai, Q., Liu, J., "Formation of Nanocrystalline Tungsten by Selective Laser Melting of Tungsten Powder", Materials and Manufacturing Processes, 27, 2012, 1267-1270.

[4] Xiao-Feng, Z., Chang-Chun, G., Yu-Jie, L., ShuangQuan, G., Wei-Liang, L., "Experimental study of Tungsten and Tungsten Alloy Coating produced by Cold Gas Dynamic Spray and Tungsten Particles Calculation and Simulation", Acta Physica Sinica, 2, 2012.
[5] Zhong, M., Liu, W., Ning, G., Yang, L., Chen, Y., "Laser Direct Manufacturing of Tungsten Nickel Collimation Component", Journal of Materials Processing Technology, 147, 2004, 167-173.

[6] Bray. M., Cockburn, A., O’Neill, W., "The Laser-assisted Cold Spray Process and Deposit Characterization", Surface \& Coatings Technology, 203, 19, 2009, 2851-2857.

[7] Lupoi, R., Sparkes, M., Cockburn, A., O’Neill, W., "High Speed Titanium Coating by Supersonic Laser Deposition", Material Letters 65, 2011, 3205-3207

[8] Lupoi, R., Cockburn, A., Sparkes, M., Bryan, C., Luo, F., O'Neill, W., "Hardfacing steel with nanostructured coatings of Stellite-6 by Supersonic Laser Deposition", Light: Science \& Applications, 1, (1), 2012, 1-6.

[9] Jones, M., Steinlage, G., Rogers, K., Poquette, B., "X-ray Tube Component Additive Surface Modification", Defensive Publication 265215, 2013 